\title{
Data and Inquiry Driving School Improvement: Recent Developments in England
}

\author{
Peter Earley - Sara Bubb
}

Institute of Education, University of London

doi: 10.7358/ecps-2014-009-earl

p.earley@ioe.ac.uk

s.bubb@ioe.ac.uk

\section{DATI E LE INDAGINI COME MOTORI DEL MIGLIORAMENTO DELLA SCUOLA: RECENTI SVILUPPI IN INGHILTERRA}

\begin{abstract}
In this paper we draw upon recent developments in England to show how school leaders are using evidence and data for the purposes of school improvement and teachers are becoming more «research engaged» or research orientated. Particular interest is given to how schools are attempting to close the gap between the performance of children from different socioeconomic backgrounds. A policy initiative - the Pupil Premium - has led to school leaders looking closely at a range of improvement and intervention strategies, their effectiveness and the impact they have, especially on poor pupils. We consider this and other related developments further, within an emerging self-improving system, and argue that school leaders are crucial for both data-driven improvement and for ensuring that school-based decision-making becomes evidence based or at least evidence informed. Research engagement does not just happen - it has to be led and managed. The vision is to change the culture of schooling so that practitioner inquiry and research engagement are important parts of teachers' professional practice. Inquiry-based school systems have been found to be a hallmark of high performing countries (Mourshed et al., 2010) and school leaders are key to the success of this system and cultural change. The paper concludes by considering what factors are important for this change to be realised.
\end{abstract}

Keywords: Evidence informed decision-making, Intervention strategies, Research engaged schools, School improvement, School leaders. 
Countries around the world are working hard to improve the education of their children and young people. The United Kingdom spends more per head on education than the OECD average, however that is not reflected in its performance. A report by the Organisation for Economic Co-operation and Development (OECD , 2014) analysed the maths results and background of more than half a million 15-year-olds who took part in the 2012 Programme for International Student Assessment (PISA) study. UK students whose parents work as professionals do not perform as well in mathematics as children of professionals in other countries - and nor do they perform as well as the children in Singapore, whose parents work in manual occupations, as seen in Figure 1. The children of parents with a "professional» job, such as doctor or lawyer, scored 525.94 points on average in the UK but 609.45 in Singapore and 656.06 in Shanghai. Children of parents with "elementary» occupations, such as cleaners and catering assistants, scored 460.61 points on average in the UK but 533.58 in Singapore and 568.9 in Shanghai. The gap in attainment between pupils has been described as England's long tail of underachievement. Other countries do not have such a gap: Finland and Japan achieve high levels of performance by ensuring that the children of parents who work in elementary occupations are given the same education opportunities and encouragement as the children of professionals.

Student performance in mathematics

in Singapore and the United Kingdom, by parents' occupations

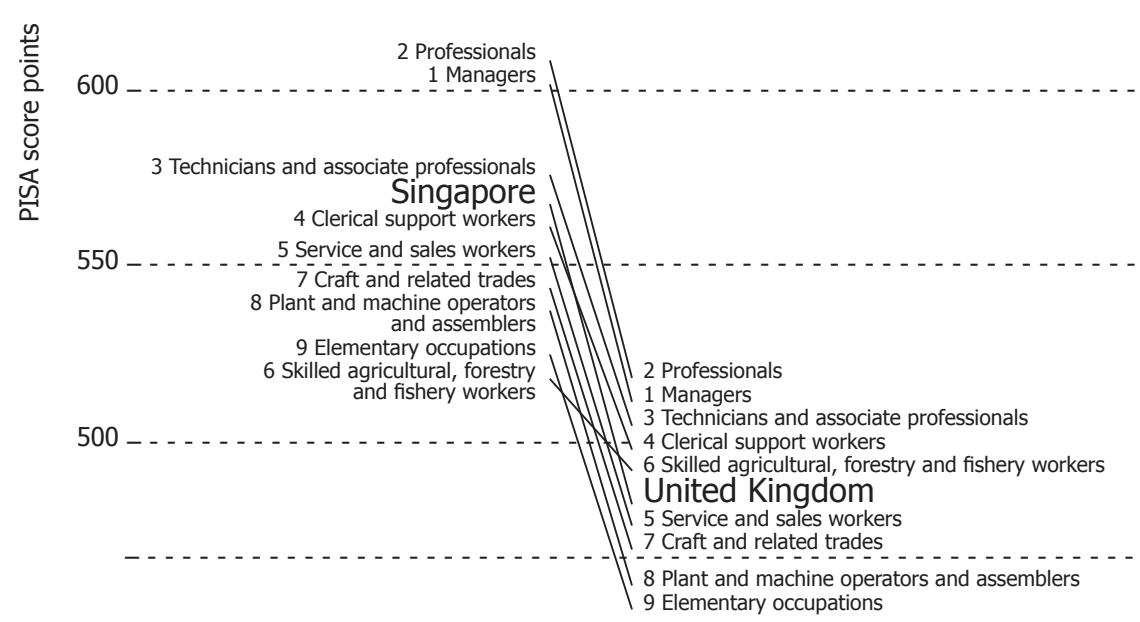

Figure 1. - Student performance in mathematics in Singapore and the United Kingdom, by parents' occupations (OECD, 2014, p. 4). 


\section{ENGLAND's SOlution - THE PUPIL PREMiUm}

An educational initiative, the Pupil Premium, introduced by the government in 2011, gave schools in England additional resources (approx. 1000 Euros per pupil in 2014) to help narrow the attainment gap between children entitled to Free School Meals (FSM), which is a proxy for economic disadvantage, and the rest of the school student population. A condition of the additional funding for children with FSM entitlement was that schools were obliged to evaluate the impact of their use of Pupil Premium (PP) funds.

Schools must report annually on their website to parents and provide evidence of impact when the school is inspected by the national agency Office for Standards in Education (Ofsted). This policy initiative has led to school leaders looking closely at a range of improvement and intervention strategies, their effectiveness and the impact they have, especially on poor pupils.

\section{AN EVIDENCE-INFORMED PROFESSION}

The introduction of the Pupil Premium resource to fund interventions has occurred at the same time as there has been a renewed interest in England in teaching becoming an evidence-informed profession. The notion of practitioner inquiry and research engagement has been exemplified with the introduction of further initiatives within schools to close the performance gap and to raise standards more generally.

Schools are being encouraged and funded to promote intervention strategies and to evaluate their impact. Schools in England are currently deploying a range of research and inquiry methods to collect both quantitative and qualitative data and making stronger links with universities. In this paper we consider these recent developments further, within an emerging self-improving system, and argue that school leaders are crucial for both data-driven improvement and ensuring that teaching (and leading) become evidence based or at least evidence informed.

Research engagement does not just happen - it has to be led and managed. The vision is to change the culture of schooling so that practitioner inquiry and research engagement are important parts of teachers' professional practice. Inquiry-based school systems have been found to be a hallmark of high performing countries (Mourshed et al., 2010).

School leaders are key to the success of this system change and cultural change, and the paper concludes by considering what factors are important for this to be realised. 


\section{TOWARDS A SELF-IMPROVING SYSTEM: RESEARCH ENGAGEMENT}

Being engaged in research and inquiry is not a new phenomenon but it has re-entered the educational debate in a significant way in recent years. As Nelson and O'Beirne (2014) state in a recent review entitled Using evidence in the classroom: What works and why?, greater school autonomy has increased teachers' responsibility and accountability to find evidence about what works in improving educational outcomes.

In addition, in England the establishment of Teaching Schools (similar in concept to the more familiar notion of Teaching Hospitals), the introduction of the Pupil Premium and other related developments have led to a renewed interest in "research engagement» and the role of research in teacher education (BERA, 2014). In England, schools are awash with data and have been using it for self-evaluation and school improvement purposes for many years (Chapman \& Earley, 2010; Kelly \& Downey, 2011). School and pupil target-setting have become commonplace especially in relation to the key performance indicators by which schools are assessed. Schools' performance especially in relation to pupil attainment and their results in public tests and examinations, are reported annually in performance tables (commonly referred to as league tables) and along with regular external inspections, have become part of a high stakes education system with a strong accountability culture (Earley, 2013). Inserting a school's name and postcode into the Department for Education's website provides parents and others with a wealth of data about that school including financial expenditure and the average salary of its teachers.

Using such data is important for driving forward school improvement, especially in relation to attainment data and target-setting but information, data and evidence from research more generally is an important part of being a research learning community or a «research engaged school». Educational leaders can use data generated inside and outside the organisation (e.g. RaiseOnline, sent to schools annually from Ofsted, reports pupil attainment and compares this with schools of a similar type and nationally) but can also make use of data and research evidence to engage with and use the findings of externally generated research or to conduct site-based practitioner inquiry, drawing on the methodological approaches and findings of previous research. Staff need to be "research literate» in the sense of «knowing how to read and interpret findings from research and knowing how much weight to accord evidence from different sources» (BERA, 2014, p. 30).

All members of the school workforce can get involved in research and inquiry although it has to date, in England and elsewhere, been dominated by teachers. Schools and colleges that are inquiry-driven are often referred 
to as «research-engaged», «self-evaluative», «reflective», «thinking», «learning organisations», professional learning communities, research learning communities or «learning-centred». However, the involvement of teachers and schools in research and inquiry has not been unproblematic. For some it is seen as a laudable extra if the time can be found for it or an indulgence that can be ill afforded especially as its benefits are not clear cut or unequivocal. For others practitioner inquiry is a core feature of reflective practice and professional development making a clear contribution to improving the quality of learning and teaching. It is argued that it can be used to help raise standards and to narrow the attainment gap between the highest and lowest student performers.

For Nelson and O'Beirne (2014, p. vi) the case for teachers engaging with evidence «is that teaching practice and learner outcomes can potentially be enhanced by effective identification and application of the evidence around the most effective approaches to teaching and learning».

Godfrey (2014, p. x) sums up the benefits of research engagement well when he states it seeks: to promote a critical engagement with research (however defined) and one that acknowledges the role of teachers as professionals free to use their own judgement to interpret and incorporate research findings in the context of their practices (e.g. Saunders, 2004 and 2006). This stance towards research can be seen as an antidote to prescriptive, top-down approaches to evidence-based education, the latter relegating teachers to «implementers» rather than «enquirers». Teachers in such schools would be critical of received wisdom, to be sceptical of easy answers, to have a desire for evidence and to foster «aggressive curiosity». (Handscomb \& MacBeath, 2003, p. 4)

Perhaps many teachers would not readily engage with the notion of being a "teacher-researcher» and so a more helpful term, which describes the skills that are part of good teaching, is the "teacher as inquirer». As Handscomb, a leading advocate of research engagement, notes:

This alludes to teachers who are keen to reflect upon and critique their practices. They make good use of research and evidence to stimulate new ways of thinking and to try out new ideas, and then systematically to evaluate the impact of any subsequent change they have brought about. (Handscomb, 2007, p. 85)

For Handscomb (2007) there are two views on evidence-informed practice. One view is of the individual teacher reflecting on classroom practice and sharing this with colleagues, in contrast to larger-scale more systematic inquiry. Another view is that these are two ends of a continuum in which «evidence-informed practice» merges into «research». There are tensions between academic research and teachers pursuing research as part of their 
professional learning and practice. Many have become convinced of the potential of practitioner research to transform the classroom and the teacher (Handscomb, 2007, p. 86).

For Handscomb and MacBeath (2004, p. x) «School-based enquiry and research are now being seen to make an important contribution to self-evaluation, improvement, and the professional learning of staff». Many teachers, they claim, are keen to reflect upon their work, explore different approaches, and try out new things in the classroom. Research activity provides the opportunity to support teacher inquiry and make it more systematic. The benefits of school-based inquiry are that it "helps staff to get together and reflect on pedagogy, assessment, curriculum and school leadership». Becoming engaged in research "can inspire curiosity, interest and professional discussion among the staff» (GTC(E), 2006, p. x).

The research engaged school has a research-rich pedagogy, a research orientation, it promotes research communities and it puts research at the heart of school policy and practice (Handscomb, 2007). It helps inform decision-making processes. Such schools make use of the research of others, they do research themselves and they are often part of the research of others. For Dyson, «all teachers should have an entitlement to research thinking in order to develop their role as critical users of research. All schools and colleagues should have an entitlement and perhaps a responsibility, to participate in a relevant research partnership for appropriate periods» (NERF, 2001).

Research engaged schools investigate key issues in teaching and learning, they use inquiry for staff development, turn data and experience into knowledge, use evidence for decision-making and promote learning communities (GTC(E), 2006). Inquiry can help develop staffs' professional judgement and expertise because engaging in research is a professional development activity. "It involves reflecting on your own practice, gaining new insights and making changes as a result» (ibid.). It requires a commitment to investigate and reflect on one's own practice.

Research learning communities and research engaged schools aim to align practice more closely with research, to use research to inform decisionmaking at every level, welcome being the subject of research by outside organisations, they encourage research and inquiry and have "an outward looking orientation»(Wilkins, 2011), including research based links with other schools and universities.

The importance of research and inquiry links closely with the notion of a self-improving system where school improvement rests with schools themselves. Schools and teachers are seen as learning best from one another and Teaching Schools with alliance partners are seen as leading the way (DfE, 2010). Government plans to raise standards and improve the quality of 
teachers and school leadership through school-to-school support and peerto-peer learning is referred to as a «self-improving system». A new national network of Teaching Schools, modelled on teaching hospitals, is being created, which gives outstanding schools (as judged by external inspection) the role of leading professional development and contributing to the raising of standards through school-to-school support.

This de-centralised system of a national network of Teaching Schools and Alliances also has a research and development role which includes a National Research and Development (R\&D) Network which seeks to support $\mathrm{R} \& \mathrm{D}$ activities, working with universities and in regional and national networks to share expertise, disseminate what works and learn from and with each other. These national developments have occurred at the same time that greater importance has been given to evidence-based practice, for as Goldacre, a medic commissioned by the government to consider building evidence into education, states:

By collecting better evidence about what works best, and establishing a culture where this evidence is used as a matter of routine, we can improve outcomes for children, and increase professional independence. (Goldacre, 2013, p. x)

In summary, the changing educational landscape in England and the move to a decentralised culture of self-improvement involves schools being effective in collaboration - within and across school/s - in school led professional development, school to school support, and staff learning from each other to improve their skills and practices with a key focus on improving outcomes for pupils. An important part of this landscape is a clearer understanding of research approaches and the use of data and inquiry to drive school improvement.

\section{EVIDENCE BASED PRACTICES}

As part of this changing educational landscape in England the teaching profession is being encouraged to improve its practice through the rigorous use of evidence and research. As the National College for Teaching and Leadership has stated:

There are numerous definitions of evidence-based teaching. What we mean in headline terms is that decisions and practice are based on evidence so that all teaching practice reflects both individual teaching expertise and the best and most up-to-date external evidence from systematic research. The ultimate test would be whether those making decisions could explain their choices and practice by 
referring to a robust evidence base and using logical argument and reasoning. (NCTL, 2014)

Teachers' practice should build on existing knowledge of what works and why and for evidence-based teaching to be prevalent, there must exist a supply of relevant and accessible research evidence.

Teachers use their professional judgement, knowledge of context and pupil performance data to inform decisions but rarely draw on research (see Figure 2).

As Stoll et al. (2012, p. 5) make clear:

Commitment to research engagement is an important feature of professional learning because it fosters a proper regard for evidence which can be used to change practice and improve pupil outcomes.

This greater use of research and evidence informed practice in schools in England has been brought about, in part, by the move to a self-improving system, including the establishment of a system of Teaching Schools, but two further related drivers have been significant: the need for schools to evaluate the impact of the Pupil Premium; and the introduction of the Education Endowment Foundation (EEF).

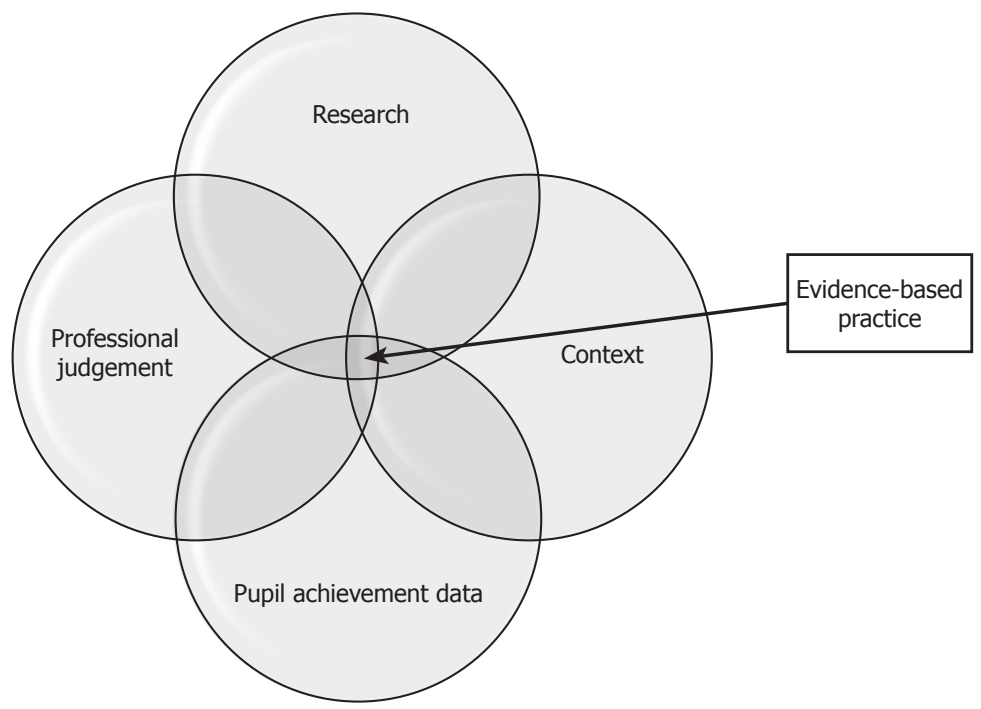

Figure 2. - Evidence-based practice. 


\section{a) Pupil Premium}

The link between poverty and educational outcomes has a long history in educational research (Smythe \& Wrigley, 2013) and although socioeconomic differences matter significantly, schools make a difference to how well a student achieves (Earley, 2013). Schools in England however have a long tail of underachievement and the differences within each one between the performance of poor children and their better off counterparts is great. Some schools have managed to close this gap entirely whilst in others the difference between the two is unacceptably high (see Table 1) and interest is increasingly being shown in why this is the case.

As noted earlier, the OECD has used the PISA results to demonstrate the tendency to overestimate the impact of poverty, showing for example that the poorest $10 \%$ of pupils in Shanghai are performing as well as the most privileged $20 \%$ of teenagers taking the test in the UK and the US, and that poor pupils in the Netherlands are as good at maths as much betteroff teenagers in France. The OECD demonstrates how academic differences attributed to social background should not be unquestioningly tolerated (OECD, 2014). This sentiment and the need to close the attainment gap have been behind the coalition government's establishment of the Education Endowment Foundation, administered by the Sutton Trust, and the introduction of the Pupil Premium.

The Pupil Premium, introduced by the Coalition government in 2011, gave schools in England additional resources (approx. 1000 Euros per FSM pupil in 2014) to help narrow the attainment gap between children entitled to free school meals (a proxy for social and economic disadvantage) and the rest of the school population. The PP is allocated to schools based on number of children eligible for free school meals at any time in the last six years, children who have been "looked after» continuously for more than six months and provides funding for two-week summer schools. Pupils whose parents are in the armed forces have a service premium of approximately 300 Euros per child.

Table 1. - Four schools in London: \% achieving 5 GCSEs ( $\left.A^{*}-C\right)$.

\begin{tabular}{cccc}
\hline Schools in London & Poor Pupils & Other Pupils & Differences \\
\hline The Cooper School & $47 \%$ & $71 \%$ & $24 \%$ \\
John Roan & $43 \%$ & $66 \%$ & $23 \%$ \\
Adeyfield School & $41 \%$ & $51 \%$ & $10 \%$ \\
Westminster Academy & $74 \%$ & $80 \%$ & $6 \%$ \\
Woolwich Poly & $76 \%$ & $77 \%$ & $1 \%$ \\
\hline
\end{tabular}


Schools have to publish online details of how they have used the PP and how successful they have been in Closing the gap. Schools are required to report to parents annually (on their website) on how the sums have been spent and what their impact has been. In addition evidence of impact has to be demonstrated during the inspection process.

As a result school leaders have looked carefully at a range of intervention strategies and the impact they have had on the performance of FSM pupils. To assist schools in making decisions about the deployment of PP funds the Teaching and Learning Toolkit - a summary of educational research, explaining what intervention strategies work and, as important, what do not - was developed (see Table 2) with support from the Education Endowment Foundation (EEF).

Table 2. - Extract from Teaching and Learning Toolkit.

\begin{tabular}{ccc}
\hline ApproaCH & MoNTHS GAIN & OvERALL cost BENEFIT \\
\hline Effective feedback & +9 & Very high impact for low cost \\
Meta-cognition strategies & +8 & High impact for low cost \\
Peer-assisted learning & +6 & High impact for low cost \\
Early intervention & +6 & High impact for very high cost \\
One-to-one tutoring & +5 & Moderate impact for very high cost \\
Homework & +5 & Moderate impact for very low cost \\
ICT & +4 & Moderate impact for high cost \\
Assessment learning & +3 & Moderate impact for moderate cost \\
Parental involvement & +3 & Moderate impact for moderate cost \\
Sports participation & +3 & Moderate impact for moderate cost \\
Summer schools & +3 & Moderate impact for moderate cost \\
Reducing class sizes & +3 & Low impact for very high cost \\
After school programmes & +2 & Low impact for moderate cost \\
Learning styles & +2 & Low impact, low or no cost \\
Arts participation & +1 & Very low impact for moderate cost \\
Teaching assistants & 0 & Very low / no impact for high cost \\
Ability grouping & +- & Very low / negative impact for no cost \\
\hline
\end{tabular}




\section{b) The Education Endowment Foundation}

The Education Endowment Foundation was set up in 2011 by the Sutton Trust, with a Department for Education grant of $£ 125 \mathrm{~m}$. It is dedicated to breaking the link between family income and educational achievement. Since its launch the EEF has awarded $£ 37$ million to 72 projects working with over 500,000 pupils in over 2,300 schools across England. Unlike previous projects that have focused on testing educational interventions, the EEF has recently awarded grants which aim to increase understanding of how schools can be supported in applying existing research findings to improve outcomes and narrow the gap. The evaluations of the «Research Use in Schools» projects will measure the impact of a range of ways for schools to engage with research and identify effective and efficient ways to share research findings.

The EEF supported the Teaching and Learning Toolkit which is an accessible summary of educational research developed at Durham University. The Toolkit covers 34 topics and summarises research from over 10,000 studies. The Toolkit is a live resource which is regularly updated as new findings are published. An extract from it is shown as Table 2. To access the Toolkit visit: http://educationendowmentfoundation.org.uk/toolki.

The Teaching and Learning Toolkit was based on meta-analyses and is very much practitioner focused. Its aim was to give schools the information they need to make informed decisions about intervention strategies that might work in their context to narrow the gap between rich and poor (or at least those pupils on FSM and the rest).

Another related development, the Closing the gap: Test and learn initiative with Teaching Schools is also worth noting. This centrally-funded scheme provides opportunities for schools to undertake research, so that:

- successful approaches to supporting the most disadvantaged children to achieve academic success are identified and spread between schools and across the teaching profession;

- stronger links between the teaching profession and universities are built, helping to develop the academic standing of the teaching profession overall ${ }^{1}$.

The vision of these initiatives is bold - it is to change the culture of education so that research engagement is an important part of teachers' practice. In Goldacre's (2013) terms it is about building evidence into education. It is intended to inform teachers' own practice and that of others within schools through the use of robust evidence, with a direct impact on educational out-

1 http://www.education.gov.uk/nationalcollege/index/about-us/national-college-role/ national-college-consultations/testandlearn.htm. 
comes. Support has been given to schools to test a range of interventions, which is seen as complementing work supported by the EEF and wider efforts to develop an evidence-informed teaching profession. In 2014 approximately 1000 English schools (about 5\%) were involved in Randomised Control Trials (RCTs) and the EEF is currently trialling approximately 70 ways of improving standards for the poorest pupils in English schools. There continues to be a debate about the appropriateness of RCTs within an educational context.

As part of the above initiatives and the more general encouragement for schools to become research engaged and evidence based, Durham University was also commissioned to produce a Do-it-Yourself (DIY) evaluation guide. The DIY Guide introduces the key principles of educational evaluation and provides guidance on how to conduct small-scale evaluations in schools. It outlines a range of options open to schools who want to evaluate carefully any new strategies or interventions and provides practical advice on designing and carrying out evaluations.

Interestingly, the guide states that «it is important to make a distinction between DIY evaluation, which can be undertaken by teachers and take place in a single school or class, and other forms of evaluation such as RCTs, which will usually take place across large groups of schools and be led by full-time researchers» (2013, p. x). Evaluation is necessary to determine if an intervention is having the desired impact and large-scale evaluations provide the best estimate of an intervention's average effectiveness. Both forms of evaluation (DIY and RCTs) are useful - they are complementary - but they serve different purposes.

The guide's outcome measures are limited as the focus is only on measuring academic attainment choosing data derived from national assessments, standardised tests from reputable suppliers or those designed by the schools. The guide is primarily about impact evaluation - understanding whether or not an intervention has had an impact on attainment. However, in addition to impact evaluation, process evaluation can be used alongside to understand how the intervention was delivered on the ground. Various kinds of qualitative and quantitative data can be collected. Process evaluation data are complementary but it is argued they are no substitute for impact evaluation data. The former can tell you how something has worked not whether it has been successful or not. The DIY evaluation guide also provides information about analysing results using spreadsheets so that an «effect size» for the school's intervention strategy can be calculated. Evidence can therefore be provided of what is effective to improve learning i.e. becoming a research engaged school encouraging the use of evidence to inform practice. It is here that the role of school leaders is key, especially in creating a culture of research and inquiry. 


\section{Changing the CUlture}

In research learning communities or research-engaged schools, research and inquiry "permeate all aspects of its life, including teaching and learning, professional development and school planning and decision-making» (Handscomb, 2007, p. 87). It is part of the culture and leaders and teachers in such communities will be encouraged to develop a critical understanding of the values, limitations and impact of research evidence and data. For research engaged school leaders there is a need to develop this criticality in relation to accessing research and data, distinguishing between good and bad research and data, and knowing how to acquire and generate data and relevant evidence to support decision-making for school improvement. Staff within such schools will develop their research literacy and be encouraged to become critical readers and active researchers through engagement with research findings, evidence-based policy documents and data packages. The school will aim to have a culture that develops and sustains critical reflection and inquiry to secure continuous improvement. It will strive to be a learning organisation building in time for collective inquiry, reviewing evidence, evaluating impact of interventions and continually striving for betterment.

Leadership in such schools involves developing and shaping a research and inquiry culture which means being prepared to commit resources (especially staff time) e.g. time to undertake inquiry and discuss research findings; identifying topics and foci for research; creating research teams (collaborative work); putting appropriate support in place, e.g. mentoring, research expertise; anticipating pitfalls and problems; creating a supportive learning culture and embedding research engagement throughout the organisation (for further details see NCSL, 2006).

For Godfrey (2014) an understanding of the growth of a school research culture or a research learning community must be seen as occurring within an interconnected ecosystem consisting of four «nourishing» factors. These are systemic connectedness; leadership for knowledge creation; teaching as a research-informed practice; and the school as a learning organisation. Godfrey explains each in detail and urges school leaders to consider developing a culture of research engagement as a long-term, sustainable school improvement strategy.

The key cultural and professional development conditions for becoming a research-engaged school were also identified by Sharp et al. (2006, p. 8) as a culture that values openness, reflection and professional debate. A commitment to using evidence for school improvement, a commitment of resources to the project, access to sources of expertise and support, a desire for people to work collaboratively (regardless of role or status) and a willingness 
to embed research activity into existing school systems such as staff development activities were all important factors. In such schools staff know that «any effort they put into doing research would be recognised and supported, and that the results would be taken seriously» (NCSL, 2006, p. 9). As the National College further note «research activity helped to promote learning among staff, encouraged staff to empathise with learners, and helped young people to recognise that their teachers were learners too» (ibid.).

\section{CONCLUSION}

Research and inquiry in schools is not new but the greater emphasis recently on the use of research and evidence to inform professional practice and drive school improvement has been brought about in England, in part, by the move to a self-improving system or what the Secretary of State described as a «decentralised culture of self-improvement in schools» (DfE, 2010). The Government wants teachers to be able to use research to inform their practice and raise standards in schools, believing that the use of robust evidence will help improve the quality of teaching and support a school-led system.

For Godfrey (2014) «the advantage of a teacher engaging in (doing) and/or with (accessing/using) research is that he/she is modelling a researching and knowledge construction approach to learning». For him research activity «brings out skills of information technology, criticality and networking in teachers that they will need if they are seeking to pass on this way of learning to their students» (p. 11). However, as Nelson and O'Beirne remark:

Teacher-led research or enquiry is not a homogenous activity. It serves different purposes and uses a variety of methods. At its most effective, the methods used are closely linked to, and fit for, purpose. It can be conceived to inform a national knowledge base, to support school self-evaluation or improvement or to support individual-level professional development, for example. (Nelson \& O’Beirne, 2014, p. vii)

Research and Development (R\&D) is one of the key components of the new Teaching Schools and it is important for them to share expertise, disseminate "what works" and learn from and with each other. Headteachers and $R \& D$ leaders of these schools are charged with disseminating and embedding approaches to evidence-based teaching so that the capability and capacity are advanced within and beyond their Teaching School alliances. However, several further drivers have been significant: the need for schools to evaluate the impact of the Pupil Premium, the introduction of the Education 
Endowment Foundation and the wider movement promoting an evidencebased approach to school-based decision-making (e.g. Wilkins, 2011; Goldacre, 2013). The British Education Research Association (BERA, 2014) has entered the debate and published the results of an inquiry into the contribution research can make to school improvement, concluding that «there is substantial evidence that research has a major contribution to make to effective teacher education in a whole variety of different ways. There is also some robust evidence that doing so improves the quality of students' learning in schools" (ivi, p. 30).

For BERA there is strong evidence that teachers need:

[...] to be equipped to engage in enquiry-oriented practice - having the capacity, motivation and opportunity to use research-related skills to investigate what is working well and what isn't fully effective in their own practice. Using data from a number of different sources teachers can identify problems together with interventions which are likely to lead to improvements. (ibid.)

For both Handscomb (2007) and Sharp et al. (2006) research engagement involves a combination of features - dedicated resources, teamwork, strong leadership, a supportive school culture and a determination to develop research communities within and beyond the school. Schools wishing to improve their performance will value highly staff development and research and encourage reflection and questioning. Research engaged schools and learning communities will use data and inquiry to help bring about school improvement but the role of the school leader in promoting such a culture should not be underestimated.

School leaders are crucial for both data-driven improvement and ensuring that teaching (and leading) become evidence based or at least evidence informed. The vision is to change the culture of schooling so that practitioner inquiry and research engagement are important parts of teachers' professional practice. School leaders are key to the success of this cultural change and need to become convinced of the potential of practitioner inquiry and the evaluation of interventions to transform schools and drive improvement and not only in relation to attainment in core subjects such as numeracy and literacy. The evidence base from such interventions is growing (e.g. see EEF website) but it is likely to be many years before such practices become commonplace and schools routinely draw upon evidence, both internally and externally generated, to inform decision-making processes. The use of attainment or pupil performance data to set targets is commonplace in English schools, there is now a need to develop this further to consider how wider school practices can be usefully informed by evidence of what works and what doesn't. As David Hargreaves said in 1996: «Teaching is not at present a 
research-based profession. I have no doubt that if it were, teaching would be more effective, and more satisfying» (Hargreaves, 2007). We might add that it would also be beneficial to students! BERA states:

Although there has been a strong focus on the use of data to inform teaching and instruction over the past 20 years, there now needs to be a sustained emphasis on creating «research rich» and «evidence rich» (rather than simply «data rich») schools and classrooms. Teachers need to be equipped to interrogate data and evidence from different sources, rather than just describing the data or trends in attainment. (BERA, 2014, p. 30)

In England there is an increasing interest in research knowledge and research mobilisation and many organisations are seeking to improve the link between research and practice. The challenges for schools in accessing and using research evidence include a shortage of time, an overload of information, and the difficulties of assessing the applicability of research. Some argue that system change will not occur without coordinated action, including the development of an infrastructure to support knowledge exchange (Nelson \& O'Beirne, 2014). However, a characteristic of high-performing education systems is their ability to make effective use of research in schools (Mourshed et al., 2010). This paper has attempted to describe recent developments in English schools to move in this direction giving particular attention to the role of school leaders in promoting research and inquiry, especially that which aims to "close the gap" between pupils from poor backgrounds and the rest.

\section{REFERENCES}

BERA (2014). The role of research in teacher education: Reviewing the evidence. London: British Educational Research Association.

Chapman, C., \& Earley, P. (2010). School inspection / external school evaluation. In P. Peterson, E. Baker, \& B. McGaw (Eds.), International encyclopedia of education, Vol. 3 (pp. 719-725). Oxford: Elsevier.

Department for Education (2010). The importance of teaching. Norwich: TSO.

Earley, P. (2013). Exploring the school leadership landscape: Changing demands, changing realities. London: Bloomsbury.

General Teaching Council (England) (2006). Using research in your school and your teaching: Research-engaged professional practice. London: GTC.

Godfrey, D. (2014, forthcoming). Leadership of schools as research-led organisations in the English educational environment: Cultivating a research engaged school culture. Educational Management, Administration and Leadership. 
Goldacre, B. (2013). Building evidence into education. http://media.education.gov. uk/assets/files/pdf/b/ben\%20goldacre\%20paper.pdf.

Handscomb, G. (2007). Collaboration and enquiry: Sharing practice. In S. Bubb \& P. Earley, Leading and managing continuing professional development (2nd ed.). London: Sage.

Handscomb, G., \& MacBeath, J. (2004a). Professional development through teacher enquiry. Professional Development Today, 7, 6-12.

Handscomb, G., \& MacBeath, J. (2004b). The research engaged school. Essex County Council.

Hargreaves, D. (2007). Teaching as a research-based profession: Possibilities and prospects (The Teacher Training Agency Lecture 1996). In M. Hammersley (Ed.), Educational research and evidence-based practice. London: Sage.

Kelly, A., \& Downey, C. (2011). Using effectiveness data for school improvement: Developing and utilising metrics. Abingdon: Routledge.

Mourshed, M., Chijioke, C., \& Barber, M. (2010). How the world's most improved school systems keep getting better. London: McKinsey.

Nelson, J., \& O'Beirne, C. (2014). Using evidence in the classroom: What works and why? Slough: NFER.

NCSL (2006). Leading a research-engaged school. Nottingham: NCSL.

NCTL (2014). Evidence-based teaching: Advancing capability and capacity for research in teaching schools. Tender document (LTF933). London: NCTL.

NERF (2001). The impact of educational research on policy and practice: Subgroup Report of National Education Research Forum. Slough: NERF.

OECD (2014). Do parents' occupations have an impact on student performance? PISA in Focus 36. Paris: OECD.

Sharp, C., Eames, A., Saundes, D., \& Tomlinson, K. (2006). Postcards from researchengaged schools. Slough: NERF.

Smythe, J., \& Wrigley, T. (2013). Living on the Edge: Rethinking poverty, class and schooling. New York: Peter Lang Publishing.

Stoll, L., Harris, A., \& Handscomb, G. (2012). Great professional development which leads to great pedagogy: Nine claims from research. Nottingham: NCSL.

Wilkins, R. (2011). Developing the research-engaged school. London: Institute of Education.

\section{RiassunTO}

In questo lavoro attingiamo ai recenti studi realizzati in Inghilterra che mostrano come $i$ dirigenti scolastici stiano utilizzando testimonianze e dati empirici per migliorare la scuola e come gli insegnanti stiano diventando sempre piu «impegnati nella ricerca" $o$ "orientati 
alla ricerca». Particolarmente interessante è il modo in cui le scuole cercano di colmare il divario tra le performances dei bambini provenienti da diversi "background» socioeconomici. Una iniziativa politica - chiamata Pupil Premium - ha portato i dirigenti scolastici a considerare una serie di strategie di intervento, l'efficacia e l'impatto che queste hanno, in particolare, per gli alunni poveri. Consideriamo questo, e gli eventuali sviluppi, come elementi all'interno di un emergente sistema di auto-miglioramento, e riteniamo che $i$ dirigenti scolastici siano figure cruciali sia per un miglioramento basato su dati empirici, sia per garantire che il processo decisionale nella scuola sia basato sull'evidenza o almeno informato da ciò che è evidente. Il coinvolgimento delle scuole nella ricerca non si è ancora compiuto, e deve essere guidato e gestito; l'idea è quella di cambiare la cultura della scuola in modo che l'indagine e l'impegno nella ricerca siano parti importanti della pratica professionale degli insegnanti. I sistemi scolastici basati sulle indagini empiriche si sono rilevati un marchio di garanzia in vari Paesi (Mourshed et al., 2010) e i dirigenti scolastici possono essere considerati gli elementi chiave per il successo di questo sistema e per il relativo cambiamento culturale. Vengono presi in considerazione i fattori ritenuti importanti per la realizzazione di questa trasformazione.

Parole chiave: Dirigenti scolasctici, Miglioramento della scuola, Processo decisionale basato sull'evidenza, Scuole impegnate nella ricerca, Strategie di intervento. 